\title{
SIFAT MAGNETISASI DAN EFEK GMR PADA SISTEM LAPISAN TIPIS TOP SPIN VALVE NiFe/Cu/NiFe/NiO
}

\author{
Tri Mardji Atmono \\ P3TM - Badan Tenaga Nuklir Nasional
}

\begin{abstract}
ABSTRAK
SIFAT MAGNETISASI DAN EFEK GMR PADA SISTEM LAPISAN TIPIS TOP SPIN VALVE $\mathrm{NiFe} / \mathrm{Cu} / \mathrm{NiFe} / \mathrm{NiO}$. Telah dilakukan preparasi dan karakteriasi sistem lapisan tipis yang yang membentuk top-spin-valve yang terdiri dari lapisan free layer $\mathrm{NiFe} \mathrm{I,} \mathrm{spacer} \mathrm{Cu}$, dan lapisan antiferromagnetik NiO yang mengikat lapisan magnetik NiFe II menjadi pinning layer. Lapisan dengan susunan tertentu yang membentuk sistem $\mathrm{NiFe} / \mathrm{Cu} / \mathrm{NiFe} / \mathrm{NiO}$ tersebut telah berhasil dibuat dengan metoda sputtering, kemudian dilakukan karakterisasi. Pengukuran hubungan antara medan magnet dengan tahanan lapisan tipis menunjukkan hasil efek GMR yang signifikan, berkisar antara 0 - .4,5\%. Pengamatan kurva histerisis yang merupakan hubungan antara magnetisasi dengan medan luar menunjukkan suatu sstem yang terdiri dari free layer, pinning layer dan spacer. Hal ini merupakan realisasi dari sistem lapisan dengan sifat exchange-coupling seperti $R K K Y$ antar thin films. Dengan menggunakan $\mathrm{Cu}$ sebagai spacer, muncul efek antisimetris dari efek GMR yang kemungkinan disebabkan oleh anisotropi yang terjadi pada saat pertumbuhan thin film. Sifat tersebut diperkuat oleh adanya pengaruh medan luar $H$ sebesar 50 Oe pada saat preparasi.. Efek magnetoresistance yang teramati merupakan GMR-ratio yang disebabkan oleh medan magnet luar, sehingga terjadi hamburan elektron pada batas antar lapisan.Pengukuran hiterisis menunjukkan "pinning" yang mengikat permaloy NiFeII secara antiferromagnetik pada lapisan $\mathrm{NiO}$ yang diikuti oleh pergeseran gaya koersitiv yang cukup besar, berkisar 30-75 gauss.
\end{abstract}

\section{ABSTRACT}

THE MAGNETIC BEHAVIOURS AND THE GMR EFFECT OF TOP-SPIN-VALVE THIN FILM SYSTEM NiFe/Cu/NiFe/NiO. The preparation and the characterization of system thin film in the form of top spin valve containing free layer $\mathrm{NiFe}$, spacer $\mathrm{Cu}$ and antiferromagnetic layer $\mathrm{NiO}$, which pinned the magnetic layer NiFeI as pinning layer, has been done. This layer system with the defined structure to form $\mathrm{NiFe} / \mathrm{Cu} / \mathrm{NiFe} / \mathrm{NiO}$ was able to be prepared by the the sputtering method, followed by the characterization. The measurement of the relation between the magnetic field and the resistance showed the GMR effect which was significant, in the range of 0 - 4.5\%. Observing the hysterisis curve, i.e the magnetization as function of the applied field, has indicated that the prepared sample was composed of free layer, pinning layer and spacer. It was the realization of the layer system with the exchange coupling like RKKY between thin films. By using $\mathrm{Cu}$ as spacer, it was obtained the effect of anti-symmetric of GMR, which may be caused by anisotropy, formed during the growing of the films. This behaviour was intensed by the external field $\mathrm{H}$ of 50 Oe applied during the preparation process. The observing effect of magnetoresistance was the GMR-ratio caused by the applied magnetic field, resulted the electron scattering at the boundaries of the layers. Measurement of the hysterisis showed the pinning which bound the permalloy NiFeII to the NiO layer antiferromagnetically followed by the shifting of the coercive force in the range of 30-75 gauss.

\section{PENDAHULUAN}

$\mathrm{P}$ erubahan resistansi suatu material yang diakibatkan oleh medan magnit luar telah sejak lama dikenal, terutama setelah Baibich /1/ pada tahun 1988 menemukan efek Giant Magnetoresistance (GMR) pada sistem multilayer $\mathrm{Fe} / \mathrm{Cr}$.
Perubahan besarnya tahanan listrik dari sistem tersebut mencapai lebih dari $20 \%$. Phenomena yang sama dengan efek ini antara lain adalah Efek Hall, dimana perubahan tahanan hanya mencapai beberapa \%, AMR (Anisotropy Magnetoresistance) mencapai beberapa \% dan Tunnel 
Magnetoresistance (TMR) yang bisa mencapai beberapa puluh \%. Aplikasi dari gejala ini antara lain adalah untuk pengukuran medan magnet, sebagai head pada sistem data storage /2/, pengukuran putaran mesin dll. Dalam hubungannya dengan logam peralihan yang bersifat magnetik dan sekaligus sebagai penghantar, efek dari GMR memegang peranan yang sangat penting karena perubahan tahanan listrik yang sangat besar. Timbulnya perubahan resistansi pada GMR terutama disebabkan oleh hamburan partikel bermuatan yang bergantung dari spin, yaitu spin up $(\uparrow)$ dan spin down $(\downarrow)$. Oleh adanya medan magnet luar yang menyebabkan exchange- coupling, terjadi pergeseran state tenaga yang tergantung dari arah spin. Arah dari pergeseran tsb adalah saling berlawanan untuk masing-masing spin ( up dan down). Besarnya pergeseran ini kira-kira adalah 1 eV pada logam Ni. Untuk ke arah bawah (sebesar kira-kira $1 \mathrm{eV}$ pada logam Ni). Banyaknya state yang berada dibawah Ferminiveau untuk elektron dengan spin down akan lebih besar, artinya state tenaga bebas untuk spin $\downarrow$ akan lebih banyak. Oleh karenanya keboleh jadian hamburan untuk spin down adalah lebih besar dibanding spin up.

Telah banyak dilakukan penelitian pembuatan lapisan tipis magnetik beserta aplikasinya /1/. Sifat umum lapisan tipis pada dasarnya sangat berlainan dengan material massivnya ("bulk"-material) disebabkan proses preparasinya (evaporasi, Sputtering, RF-Glow discharge dll.) maupun geometrinya (panjang dan lebar » tebal) serta komposisi dan strukturnya. Salah satunya adalah untuk aplikasi dalam bidang sensor magnet. Sebelum ditemukannya lapisan tipis magnetik dengan sifat GMR, pengukuran medan magnet dilakukan dengan meggunakan batang semi konduktor kristal hall, dimana pada batang semikonduktor tersebut pada arah $\mathrm{X}$ dipasang medan magnet yang akan diukur, arah $\mathrm{Y}$ dialirkan arus listrik, maka arah $\mathrm{Z}$ akan muncul tegangan hall (akibat gaya Lorentz) yang besarnya adalah sebanding dengan kuat medan $(\mathbf{F}=\mathrm{q}$ $\mathbf{v x B}$ ). Sensor magnet semacam ini tidak praktis karena harus menggunakan sumber arus, dan juga ketepatannya tidak bisa diandalkan karena adanya interaksi antara arus dan medan. Bila magnetisasi lapisan tipis ditentukaan oleh medan luar, maka lapisan tipis tersebut bisa difungsikan sebagai sensor medan magnet lewat pengukuran tahanan. Dua mekanisme/proses untuk mengukur/ menentukan medan luar adalah bahwa medan terpasang menentukan arah dan besar magnetisasi thin film dan kemudian magnetisasi menentukan besarnya resistivitas. Efek ini muncul berdasarkan prinsip GMR (Giant-Magnetoresistance) yaitu perubahan tahanan thin film karena adanya pengaruh medan luar $/ 4 /$. Berdasarkan teori scattering, elektron dengan spin up akan diteruskan oleh lapisan dengan arah megnetisasi vertikal, sehingga mean-free-path akan bertambah, tetapi akan dihamburkan oleh lapisan dengan arah magnetisasi yang berlawanan,. Gejala demikian akan menimbulkan efek tahanan karena muatan penghantar terhamburkan "bolak-balik" di dalam sistem lapisan tipis, sebagian kecil saja yang diteruskan.Efek GMR adalah besar bila sistem lapisan saling antiparalel (antiferromagnetic-coupling) /2/. Kemungkinan akan bertambah apabila digunakan $\mathrm{Si}(100)$ sebagai substrat dan menggunakan Tantalum sebagai lapisan penutup. Realisasi dari GMR tersebut akan teramati nyata dalam suatu pseudo. Dalam suatu sistem pseudo-spin valves, dikenal dua besaran, yaitu gaya koersitif dari lapisan $\mathrm{NiFe}$ dan $\mathrm{H}$-pinning dari $\mathrm{NiFe}$ yang terikat pada lapisan antiferromagnetik NiO. Sistem ini hanya bisa dibuat dengan parameter sputtering tertentu saja dan stabil pada daerah temperatur yang juga tertentu / $1 /$. Jadi oleh sebab timbulnya perubahan tahanan oleh adanya medan luar, maka sistem tersebut bisa diaplikasikan sebagai sensor magnet tanpa menggunakan arus seperti pada metoda lama Hall, terutama untuk 
pengukuran medan kecil (bebeapa Oe sampai puluhan Oe), tergantung dari daerah linearitas lapisan $\mathrm{NiFe}$ sebagai free layer. Kemungkinan sensitivitas dari sensor magnet tersebut akan bisa dinaikkan dengan cara irradiasi pada sistem pseudospin-valves./3/.

Dalam penelitian ini dilakukan pembuatan sistem lapisan tipis yang tersusun dari lapisan free layer $\mathrm{NiFe}$, pinning- dan pinned layer, masing-masing $\mathrm{NiO}$ dan $\mathrm{NiFe}$ serta spacer $\mathrm{Cu}$. Kemudian pada sistem tersebut dilakukan karakterisasi magnetic, terutama sifat hysterisis dan elektrik untuk mengetahui sifat GMR. Dari hasil penelitian diharapkan diperolehnya pengetahuan tentang sifat GMR dari permalloy NiFe yang bisa diaplikasikan sebagai sensor medan magnet.

\section{TATA KERJA DAN PERCOBAAN}

Sistem lapisan tipis dengan susunan $\mathrm{NiFeI} / \mathrm{Cu} / \mathrm{NiFeII} / \mathrm{NiO}$ dihasilkan dengan metoda sputtering pada frekuensi radio 13,56 MHz. Frekuensi ini dipakai karena telah disepakati secara internasional dan juga agar tidak mengganggu komunikasi, disamping juga merupakan frekuensi optimal agar terbentuk tegangan self-bias yang maksimal pada katoda yang berfungsi untuk memberikan tenaga kepada ion-ion Argon Untuk mengoptimalkan daya yang digunakan pada proses pembentukan lapisan tipis, digunakan match-box yang berfungsi untuk menyesuaikan impedansi generator dengan plasma.

Dalam hal NiO- dan NiFe-thin film maka diperlukan masing-masing bahan target Ni dan Permalloy yang ditempatkan pada katoda. Untuk membentuk $\mathrm{NiO}$ maka diperlukan gas oksigen disamping juga gas argon sebagai sputter-gas. Tabel 1 di bawah ini adalah merupakan sputterparameter pada saat preparasi lapisan tipis ganda $\mathrm{NiFe} / \mathrm{Cu}$ dan antiferromagnetik $\mathrm{NiO}$ yang merupakan pinning dari $\mathrm{NiFe}$.
Tabel $1:$ Sputter parameter

\begin{tabular}{|l|l|l|}
\hline Frekuensi & 13,56 & $\mathrm{M} \mathrm{Hz}$ \\
\hline Arus katoda & 125 & $\mathrm{~mA}$ \\
\hline Tegangan DC-Bias & 1000 & $\mathrm{~V}$ \\
\hline Jarak elektroda & 60 & $\mathrm{~mm}$ \\
\hline Tekanan Argon & $3 \times 10^{-2}$ & $\mathrm{mbar}$ \\
\hline $\mathrm{O}_{2}$-flowrate & 0.8 & $\mathrm{sccm}$ \\
\hline
\end{tabular}

Secara umum semua material target ditempatkan pada katoda, sedangkan substrat pada anoda. Sistem lapisan tipis membentuk spin valves yang dapat diaplikasikan sebagai sensor medan magnet yang sangat bergantung dari kepekaan lapisan permalloy $\mathrm{NiFe}$ I sebagai free layer dalam hubungannya dengan sifat GMR. Untuk membentuk susunan tersebut sangat diperlukan parameter sputtering yang sangat peka, seperti ketebalan lapisan dan tekanan argon. NiO dengan sifat antiferromagnetik merupakan lapisan pinning dari $\mathrm{NiFe}$ II. Pengamatan histerisis, struktur mikro, pengukuran efek GMR sangat diperlukan untuk mengetahui karakter dari masing masing lapisan dan dari sistem yang terintegrasi. Gambar 1 di bawah ini adalah set-up elektronik dari sistem pengukuran efek GMR.

Daya nominal untuk RF berkisar antara $150 \mathrm{~s} / \mathrm{d} 175 \mathrm{~W}$ untuk memperoleh tegangan bias $-800 \mathrm{~s} / \mathrm{d}-1000 \mathrm{~V}$. Sebagai sputter gas adalah Argon dengan kemurnian 99,9\%. Tekanan Ar pada proses sputtering adalah $5 \times 10^{-2}$ mbar. Jarak elektroda adalah $30 \mathrm{~mm}$. Ketebalan lapisan tipis berkisar $20 \mathrm{~s} / \mathrm{d} 100$ $\mathrm{nm}$. Setelah terbentuk thin film, kemudian dilakukan karakterisasi dengan menggunakan aktivasi netron cepat untuk identifikasi unsure yang terdeposisi, X-ray untuk penelitian struktur, Untuk karakterisasi magnetik, yang merupakan titik berat dari pengukuran/ pengamatan pada penelitian ini, digunakan VSM. Pengukuran efek GMR dikerjakan dengan metoda four-point-probe (gambar 1). 


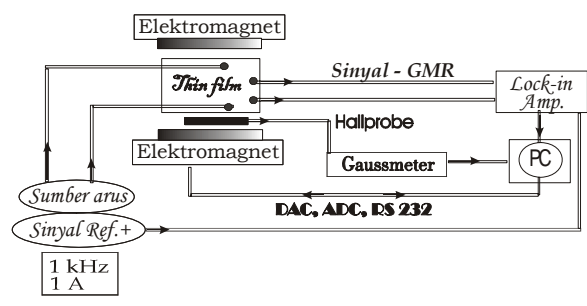

Gambar 1: Set-up sistem pengukuran efek Giant Magnetoresistance

\section{HASIL DAN PEMBAHASAN}

Ketebalan thin film dengan sifat optimal pada aplikasi dalam penelitian ini adalah berturut-turut $10 \mathrm{~nm}(\mathrm{NiFeI}), 3 \ldots 6$ $\mathrm{nm}$ untuk spacer $\mathrm{Cu}$ dan 10 sampai $15 \mathrm{~nm}$ untuk pinned layer $\mathrm{NiFeII}$ serta $50 \mathrm{~nm}$ untuk lapisan antiferromagnetik NiO. Preparasi lapisan tipis dengan menggunakan metoda sputtering yang bekerja pada frekuensi radio pada umumnya memiliki sifat yang sangat kompleks karena banyaknya parameter yang terlibat, sehingga untuk membuat thin films yang memiliki sifat yang diinginkan, sesuai dengan tuntutan aplikasinya, tidaklah mudah, bahkan sangat sulit, sehingga pada proses preparasinya telah dibuat beberapa variasi parameter terutama flow-rate dari oksigen (untuk membentuk antiferromagnetik $\mathrm{NiO}$ ) dan ketebalannya, kemudian dipilih lapisan dengan sifat optimal. Hal ini terutama berlaku untuk sistem multilayer yang memang sangat rumit dalam penyiapannya,. Sifat yang harus dimiliki oleh lapisan tipis adalah mutlak sesuai dengan sifat aplikasinya: sifat mekanik, listrik, sifat kemagnetan dll. Parameter yang terlibat dalam proses ini terutama adalah tegangan $\mathrm{RF}$ dan tegangan self-bias pada katoda, jenis gas, tekanan gas, jarak elektroda dan suhu substrat Tegangan elektroda menentukan komposisi atau kandungan unsur tertentu dalam lapisan tipis, karena adanya sifat preferential sputtering. Pada gambar 2 ditunjukkan secara kualitatif hasil pengamatan komposisi dari sistem lapisan $\mathrm{NiFe} / \mathrm{Cu} / \mathrm{NiO} / \mathrm{NiFe}$ dengan menggunakan teknik aktivasi neutron cepat. Multilayer tsb dihasilkan pada tegangan self bias $1000 \mathrm{~V}$ (DC), tegangan RF $1800 \mathrm{~V}$ dan arus katoda $120 \mathrm{~mA}$. Dengan cara mencocokkan tabel energi aktivasi netron, maka dapatlah ditentukan unsur-unsur yang menghasilkan puncak-puncak energi $\gamma$.

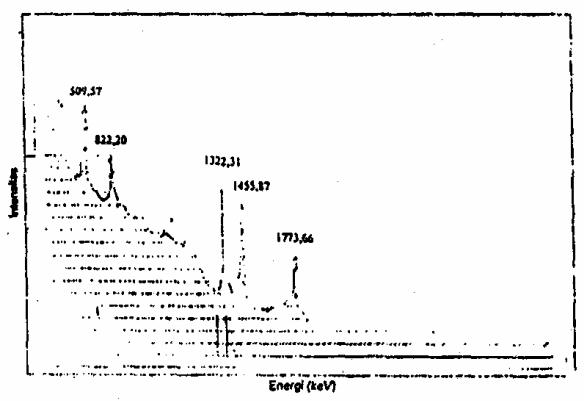

Gambar 2. Spektrum tenaga $\gamma$ dari sistem lapisan $\mathrm{NiFe} / \mathrm{Cu} / \mathrm{NiFe} / \mathrm{NiO}$

Akibat irradiasi dengan neutron cepat tersebut, sebagian inti unsur-unsur $\mathrm{Ni}$, $\mathrm{Fe}$ danCu pada multilayer akan menangkap neutron sehingga bersifat radioaktif. Selanjutnya radionuklida yang terbentuk tersebut memancarkan sinar $\gamma$ dengan energi karakteristik masing-masing untuk unsur-unsur Ni, Fe dan Cu. Dari hasil deteksi spectrometer $\gamma$, teramati puncak tenaga $\gamma$ yang dihasilkan oleh $\mathrm{Cu}$ pada nomor kanal 141,87 dengan tenaga $509,57 \mathrm{keV}$, Fe pada nomor kanal 630,14 (tenaga 1322,31 keV), Ni pada 710,95 (tenaga 1455,87) dan Si pada tenaga $1773,66 \mathrm{keV}$ sesuai dengan nomor kanal 903,87 .

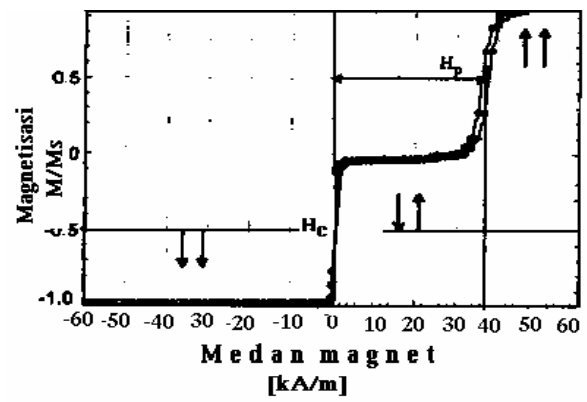

Gambar 3. Kurva magnetisasi dari system top-spin-valve $\mathrm{NiFeI} / \mathrm{Cu} / \mathrm{NiFeII} / \mathrm{NiO}$ 
Besarnya efek GMR didefinisikan sebagai perbandingan perubahan tahanan listrik akibat medan magnet luar $(\Delta \mathrm{R})$ terhadap tahanan listrik pada medan besar $\mathrm{R}_{\text {sat }}$ (beberapa $\mathrm{kA} / \mathrm{m}$ sampai diperolehnya tahanan jenuh) dirumuskan sebagai :

$$
\Delta \mathrm{R} / \mathrm{R}_{\text {sat }}=\left(\mathrm{R}_{\text {max }}-\mathrm{R}_{\text {sat }}\right) / \mathrm{R}_{\text {sat }}
$$

Dengan $R_{\max }$ adalah tahanan terbesar yang terjadi pada medan magnet tertentu, tergantung dari jenis/susunan sistem layer.

Pada gambar 3 ditampilkan hasil pengukuran magnetisasi sebagai fungsi dari medan magnet luar untuk sistem top-spin-valve $\mathrm{NiFeI} / \mathrm{Cu} / \mathrm{NiFeII} / \mathrm{NiO}$. Kurva magnetisasi ini sangat menentukan sifat GMR, karena keterlibatan parameter "pinning" Hc dan Hp seperti tampak pada gambar 3. Besarnya medan pinning Hp ini ditentukan oleh orientasi dari EA (easy axis, sumbu ringan) yang terletak sejajar pada bidang lapisan tipis (in-plane anisotropy) dan juga merupakan kontribusi dari sifat antiferromagnet dari lapisan NiO. Rate dari oksigen untuk membentuk lapisan antiferromagnetik yang berfungsi sebagai pinning layer adalah $0.8 \mathrm{sccm}$ telah mampu mengikat dengan kuat lapisan NiFeII yang merupakan referensi dari free layer $\mathrm{NiFeI}$. Pada medan negatif, orientasi dari kedua lapisan adalah parallel dan searah dengan medan luar. Apabila medan luar H tersebut dibalik arahnya maka lapisan bebas (free layer) akan terorientasi sejajar dengan $\mathrm{H}$, sedangkan lapisan yang terikat (pinned layer) akan mengikuti arah $\mathrm{NiO}$ sampai dengan $30 \mathrm{kA} / \mathrm{M}$. Pada daerah tersebut diperoleh efek GMR maksimum (gambar 4) karena muatan penghantar akan dihamburkan pada batas-batas lapisan tipis. Gejala GMR tersebut teramati pada ketebalan spacer $\mathrm{Cu}$ sebesar $3 \mathrm{~nm}$. Disini kemungkinan berlangsung kopling antiferromagnetik (AF-coupling) yang kedua sesuai dengan teori dari RKKY(Rudermann, Kittel, Kasuya, Yosida) /6/, dimana untuk ketebalan sekitar $2 \mathrm{~nm}$ terjadi kopling ferromagnetik. AF-coupling yang pertama berada di sekitar $\mathrm{t}=1 \mathrm{~nm}$.

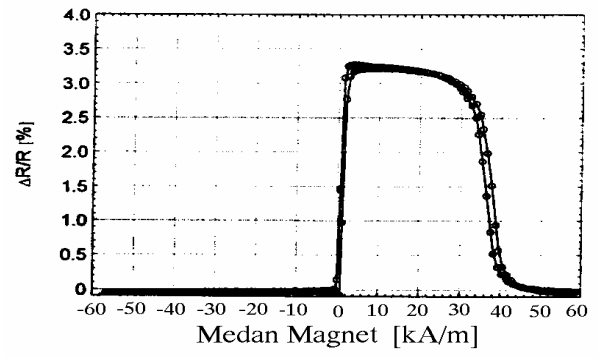

Gambar 4 . Efek GMR dari lapisan top-spinvalve $\mathrm{NiFeI} / \mathrm{Cu} / \mathrm{NiFeII} / \mathrm{NiO}$

DC-Sputtering ternyata memerlukan tegangan yang jauh lebih besar daripada metode RF /4/. Untuk tegangan self-bias yang sama dengan tegangan DC bahkan kandungan $\mathrm{Ni}, \mathrm{Fe}, \mathrm{Co}$ maupun spacer $\mathrm{Cu}$ dalam thin film jauh lebih kecil. Oleh karenanya maka sputter-yield akan berbeda untuk kedua proses tersebut. Pada lapisan tipis dengan ketebalan beberapa nm yang bersifat ferromagnetik, seperti yang dilakukan dalam eksperimen ini $\mathrm{Fe}, \mathrm{Co}, \mathrm{Ni}$ atau gabungannya seperti permalloy $\mathrm{NiFe}$, magnetisasi bisa terletak di bidang (Easy Axis // M) karena bidang thin film merupakan preferred direction, membentuk in-plane anisotropy. Orientasi $\mathrm{M}$ dengan demikian terdefinisikan tanpa adanya pengaruh medan luar. Bila thin film ini dialiri arus listrik $\mathrm{i}$ yang membentuk sudut $\theta$ terhadap magnetisasi , maka tahanan terukur merupakan fungsi sudut (i,M). Sifat GMR yang dimiliki oleh lapisan tipis ternyata juga tidak sama besarnya, tegangan RF memberikan efek yang lebih besar. Sehingga untuk preparasi lapisan tipis dengan sifat Magnetoresistance lebih tepat menggunakan tegangan pada radio frekuensi tersebut. Untuk daerah medan lebih besar dari $40 \mathrm{kA} / \mathrm{m}$, terlihat orientasi sejajar dari memen magnetik kedua lapisan (gambar 3) dan efek GMR yang dihasilkan menjadi minimal, bahkan tidak bisa difungsikan sebagai sensor. Dengan demikian pada range 
$0 \ldots 30 \mathrm{kA} / \mathrm{m}$ merupakan daerah kerja sensor magnet.

Selanjutnya, untuk mengetahui struktur mikro, telah dilakukan analisis dengan menggunakan difraksi sinar X. Pada gambar 5 ditampilkan salah satu hasil pengamatan struktur dengan menggunakan difraksi sinar $\mathrm{X}$ tersebut. Berdasarkan rumusan Bragg $2 \mathrm{~d}$ $\sin \vartheta=\mathrm{n} \lambda$, maka akan terdeteksi peak (puncak) karena interferensi konstruktiv yang menandakan struktur kristal. Sebaliknya bila struktur lapisan tipis adalah amorph maka tidak akan memberikan puncak-puncak diffraksi karena interferensi destruktiv.

Data hasil eksperimen yang ditampilkan pada gambar 5 kemudian dicocokkan dengan data literature. Diperoleh struktur kristal dengan orientasi bidang hkl berturut-turut $\mathrm{Si}(100), \mathrm{NiO}(100), \mathrm{CuO}(200)$, $\mathrm{NiFe}(111), \mathrm{Ni}(220), \mathrm{Fe}(220), \mathrm{Co}(311)$ dan $\mathrm{Cu}(311)$. Dalam hal ini Si berasal dari substrat, Co kemungkinan berasal dari sputter-chamber. Terlihat bahwa pertumbuhan kristal yang paling dominan adalah $\mathrm{NiFe}$ pada sudut $2 \theta=44,0196^{\circ}$

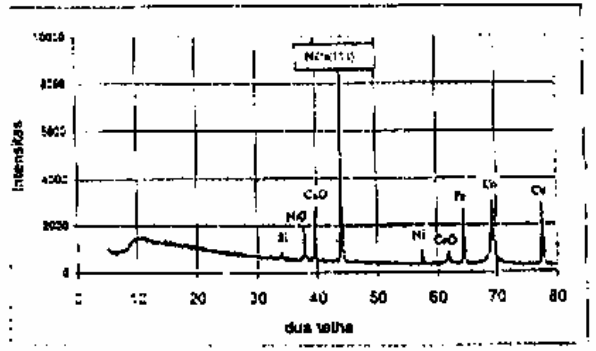

Gambar 5: Hasil pengamatan struktur dengan menggunakan XRD

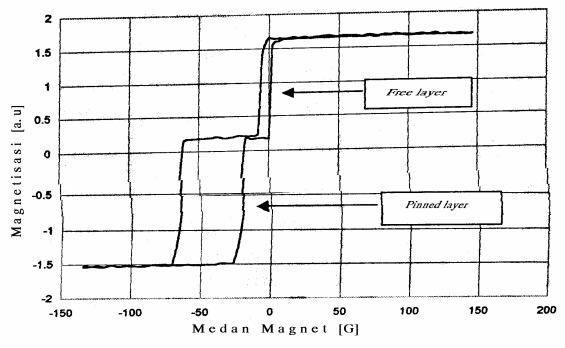

Gambar 6 :Hasil pengukuran sifat magnetik dari sistem $\mathrm{NiFe} / \mathrm{Cu} / \mathrm{NiFe} / \mathrm{NiO}$

Hasil pengukuran sifat magnetik ditampilkan pada gambar 6 . Tampak dengan jelas adanya 2 lapisan yang memiliki perbedaan gaya koersitiv, yaitu free layer $\mathrm{NiFe}$ I dan pinned layer $\mathrm{NiFe}$ II masing-masing dengan $\mathrm{Hc}=5 \mathrm{G}$ dan $\mathrm{Hc}=50$ G. Lapisan NiFe kedua tergeser sebesar $40 \mathrm{G}$ akibat dari lapisan antiferromagnetik $\mathrm{NiO}$ yang mengunci lapisan ferromagnetik tersebut. Lapisan pertama yang lebih soft yang dihasilkan dengan paraneter sputtering tertentu, kemungkinan bisa diaplikasikan sebagai sensor medan magnit. Kelemahannya disini tampaknya adalah Hc yang terlalu kecil yang membentuk sistem spin-valves, bukan pseudo karena adanya interaksi antar lapisan, indikasinya tampak pada timbulnya pergeseran kurva.

Untuk memperbesar gaya koersitiv tersebut mungkin bisa ditempuh dengan mengurangi ketebalan, tetapi kerugiannya adalah Ms yang menurun sehingga akan mengurangi sensitivitas sebagai sensor $/ 5 /$.

Berdasarkan pengukuran sifat magnetik, medan yang relativ kecil 50 Oe dalam sistem sputtering mampu membentuk easy-axis yang sejajar dengan $\mathrm{H}$ dan hard-axis yang tegak lurus bidang lapisan tipis. Pada aplikasinya dalam sistem spin-valves $\mathrm{FeNi} / \mathrm{Cu} / \mathrm{NiFe} / \mathrm{NiO}$, terjadi pergeseran gaya koersitiv $\mathrm{FeNi}$ dari lapisan tunggalnya. Dengan demikian terjadi koppling interaksi antara kedua lapisan tipis. Pengamatan Magnetoresistance Gambar 7 menunjukkan ketergantungan tahanan spin-valves dari medan magnet terpasang. Hal tersebut bisa dijelaskan dengan model spin yang terorientasi parallel dan antiparallel terhadap arah magnetisasi, yaitu spin-up dan spin down yang jelas memberikan kontribusi pada efek medan magnit luar terhadap pergeseran pita d, sehingga menyebabkan proses hamburan, menyebabkan perubahan konduktivitas logam, terutama logam peralihan (3d), juga dalam kaitannya dengan 
teori RKKY. Besarnya maksimal perubahan tahanan listrik akibat dari medan luar adalah hampir sama untuk kedua lapisan, yaitu sekitar $4,5 \%$. Teramati sifat yang tidak simetris terutama pada lapisan pinned layer terhadap medan luar, sesuai dengan kurva histerisis yang tergeser oleh lapisan antiferromagnetik. Dengan menggunakan $\mathrm{Cu}$ sebagai spacer, menunjukkan munculnya efek antisimetris dari efek GMR tersebut yang kemungkinan disebabkan oleh anisotropi yang terjadi pada saat pertumbuhan thin film. Sifat tersebut diperkuat oleh adanya pengaruh medan luar $\mathrm{H}$ sebesar 50 Oe pada saat preparasi untuk membentuk EA pada arah in-plane. Noise teramati yang besarnya sekitar $5 \%$ dari sinyal bukan berasal dari efek GMR melainkan dari sistem instrumen atau dari getaran mekanik diluar sistem pengukuran. Dari gambar 6 diperoleh indikasi bahwa system lapisan ini bisa diaplikasikan untuk sensor pada medan rendah sampai dengan 50 gauss, sesuai dengan range medan, yang menghasilkan perubahan tahanan terbesar dari pinned layer.

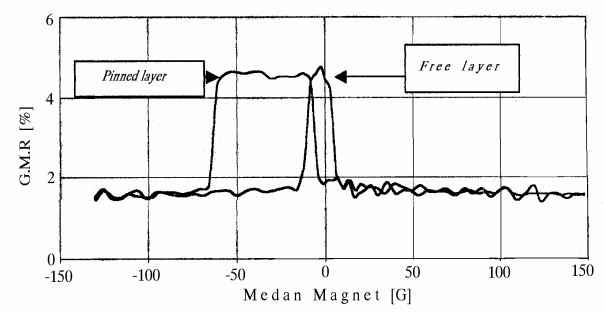

Gambar 7: Hasil pengukuran efek GMR

\section{KESIMPULAN}

Pengukuran MR pada lapisan free-layer memperlihatkan ketergantungan pada medan luar yang menunjukkan keterkaitannya dengan sistem lapisan tipis yang membentuk susunen top-spin-valve. Pada aplikasinya dalam sistem top-spin-valve ini lapisan $\mathrm{FeNi} / \mathrm{Cu} / \mathrm{NiFe} / \mathrm{NiO}$, terjadi pergeseran gaya koersitiv $\mathrm{FeNi}$ dari lapisan tunggalnya.
Dengan demikian terjadi koppling interaksi antara kedua lapisan tipis. Pengamatan Magnetoresistance menunjukkan ketergantungan tahanan spin-valves dari medan magnet terpasang, tergantung dari orientasi relatif antara free layer dengan pinned layer,menghasilkan efek GMR antara $0 \ldots 4,5 \%$ Hasil ini memungkinkan aplikasi di bidang sensor magnetik pada daerah medan antara 0 sampai $30 \mathrm{kA} / \mathrm{m}$. Sedangkan untuk medan rendah apliksai ini barda pada daerah $0 \ldots 50$ gauss. Hal tersebut bisa dijelaskan dengan model spin yang terorientasi parallel dan antiparallel terhadap arah magnetisasi, yaitu spin-up dan spin down yang memberikan kontribusi efek hamburan (scattering) yang berbeda pada efek medan magnit luar terhadap pergeseran pita d, sehingga menyebabkan proses hamburan dengan cross section yang bersifat spin-dependent, menghasilkan perubahan konduktivitas logam, khususnya sistem lapisan tipis yang membentuk spin-valve.

\section{DAFTAR PUSTAKA}

1. L. BAIBICH, M. URBANIAK, T. LUCINSKI, Molecular Physics Reports, 21,167, 1988

2. KIENEL, G., FREY. H.; Dünnschichttechnologie; VDI Verlag, Düsseldorf, 1996.

3. P.GRUENBERG, R.SCHREIBER, Phys. Rev. Letters, 5,2442,1999.

4. W.CLEGG et.al, Some aspects of Thin Film Magnetoresistive Sensors, Proceeding of the 2 nd International Conference on Physics of Magnetic Materials, Polandia 17-22 Setember 2000.

5. S.TUMASKI, Thin Films Magnetoresistive Sensors, ed Institute of Physics Publishing, Philadelpia, 2002.

6. A.FERT, F.PETROFF, Oscillatory interlayer coupling and Giantmagnetoresistance in $\mathrm{Co} / \mathrm{Cu}$ multiplayer, Journal of Magnetism and Magnetic Materials, 94, L1-L5, 1997. 